\title{
Türk Kültüründe Kuşburnu
}

\author{
Rose Hip in Turkish Culture
}

Özlem ÜNALAN 1
Araștırma Makalesi / Research Article

Geliş Tarihi / Received: 04. 02. 2021

Kabul Tarihi / Accepted: 13.09. 2021

Doi: 10.48146/odusobiad.874152

Atıf / Citation:Ünalan, Ö., (2021). “Türk Kültüründe Kuşburnu” ODÜSOBİAD 11(3), 745-762, Doi: 10.48146/odusobiad. 874152

\section{Öz}

Kültür bir toplumun sahip olduğu maddi ve manevi değerler bütünüdür. Bir toplumun gelenekleri ve görenekleri, halk inanışları, mani, masal, türkü, efsane, destan vb. ürünleri, yemekleri, halk hekimliği uygulamaları o toplumun kültürünü oluşturur. Kuşburnu, halk edebiyatı ürünlerindeki kullanımıyla, çevresinde gelişen halk inanışlarıyla ve bir besin kaynağı olarak Türk kültürü içinde kendine bir yer edinmiştir.

Anadolu'nun birçok yerinde çoğu zaman kendiliğinden yetișen kușburnu, soğuğa karșı dayanıklı ve pek çok rahatsızlığa şifa olarak görülen bir bitkidir. Kuşburnu mitolojik bir ağaç olmasının yanı sıra çeşitli halk anlatılarına konu olan, etrafında pek çok inanış ve ritüelin gerçekleștiği bir meyvedir. Hıdırellez'e, nazara, cine, büyüye, türbelere ve çocuk yetiştirmeye dair halk inanışlarında sıcça karşımıza çıkar. Anadolu'nun birçok yerinde kuşburnu üzerine türküler yakılıp maniler söylenir. Aynı zamanda dallarına bez, kurdele, çamaşır, ip vb. nesneler bağlanarak dilek ağacı fonksiyonu görür.

Kuşburnu günümüzde çayı, reçeli, meyve suyu, marmelatı, çorbası, pestili, kompostosu ile Türk mutfağının eşsiz lezzetlerinden birini oluşturur. Mucizevi bir bitki olarak görülen kuşburnu bu yönüyle halk hekimliğinde sıklıkla kullanılır. Bugün besin ve ilaç sanayisi için de önemli bir hammaddedir.

Bu çalıșmada kușburnu kültürel yönden değerlendirilecektir. Mitolojik yönü ele alındıktan sonra geçmișten günümüze kușburnuya dair inanıș ve uygulamalardan söz edilecek ardından halk hekimliğindeki yeri ve önemi üzerinde durulacaktır. Kuşburnuya dair halk edebiyatı ürünlerinden örnekler verilip Türk mutfağında kuşburnu ile hazırlanan lezzetler anlatılacaktır.

Anahtar Kelimeler: Türk Halk Bilimi, Kușburnu, Halk İnanıșları, Ritüel, Türk Kültürü.

\begin{abstract}
Culture is the whole material and spiritual values that a society has. Traditions and customs of a society, folk beliefs, mania, fairy tale, folk song, legend, epic etc. products, dishes, folk medicine practices form the culture of that society. Rosehip has gained a place in Turkish culture with its use in folk literature products, with the folk beliefs that have developed around it, and as a source of food.

Rosehip, which grows spontaneously in many parts of Anatolia, is a plant that is resistant to cold and seen as healing for many ailments. Rosehip is a fruit which is the topic of many folkloric narrations and which has many beliefs and rituals around it as well as being a mythological tree. It can be seen in many folkloric beliefs such as hidirellez, bad evil, gin, magic, tombs and growing up children. There are a lot of folkloric songs about rose hips in Anatolia. At the same time, branches of cloth ribbon washing rope and so on. objects are connected to see the wish tree function.

Rosehip is one of the most unique tastes of Turkish cuisine with its tea, jams, juice, marmalade, soup, churchkhela and composte. Rosehip, which is seen as a miraculous plant, is also used in public health. Today, it is an important raw material for the food and medicine industry.

In this study, the rosehip will be studied from cultural perspectives. First its mythological way will be handled, then beliefs and practices about rosehip from past to now present will be presented, then its place for public health will be handled. Examples from folkloric literature about rosehip will be given and flavors prepared with rosehip in Turkish cuisine will be explained.
\end{abstract}

Keywords: Folklore, Rose Hip, Folk Belief, Rituals, Turkish Culture

${ }^{1}$ Arş. Gör., Bayburt Üniversitesi İnsan ve Toplum Bilimleri Fakültesi, Türk Dili ve Edebiyatı Bölümü, ozlemunalan@bayburt.edu.tr, ORCID ID: 0000-0001-5345-6499. 


\section{Giriş}

Ağacın Türk kültürü içinde önemli bir yeri vardır. "Ağaç kozmik eksendir, hayat verendir, boy ağacı merkez fikrinin bir parçasıdır. "(Lvova, Oktyabrskaya, vd. , 2013: 43) Ağaçlara atfedilen kutsallığın, onlara duyulan saygının ve ağaçlar çevresinde gelișen inanışların kaynağı Şamanizm'e ve eski Türk inanç sistemine dayanır. Şamanlar, hasta kişilerin kaçan ruhlarını yer altında ve gökyüzünde ararken gökyüzüne ulaşmak için çeşitli ağaçları kullanmıştır. (Eliade, 1999: 318). Ayrıca şaman davulları kayın ve sedir ağacından yapılmış, bu ağaçlar özenle seçilmiş, şaman davulu üzerine kayın ağacı motifleri işlenmiş ve davulun yapımı bittikten sonra davul ardıç dalıyla tütsülenmiştir. (İnan, 1986: 96). Göktürk Kitabeleri'nde Ötüken Ormanı mukaddes bir yer olarak nitelendirilmiștir. (Ögel, 2014: 26) Oğuz Kağan destanında Oğuz Kağan'ın ikinci karısı göl ortasındaki ağaç kovuğundan ortaya çıkmıştır. (Ögel, 2010: 88) Oğuz Kağan'ın İt Barak kavmi ile savaşması esnasında askerinden biri vefat etmiş ve vefat eden askerin karısı bir ağaç kovuğunda erkek çocuğu doğurmuştur. Oğuz Han, çocuğa ağaç kovuğu anlamına gelen Kıpçak ismini koymuş ve onu evlat edinmiştir. (Roux, 1994: 165)

Dede Korkut hikâyelerinden “Kazan Bey'in Oğlu Uruz Bey'in Tutsak Olduğu Hikâye”de, Kazan Bey'in oğlu Uruz ağaçla söyleşirken "er olsun, avrat olsun korkusu ağaç" diyerek herkesin ağaçtan çekindiğini dile getirmiştir. Ayrıca " başını alıp bakacak olsam başsız ağaç, dibini alıp bakacak olsam dipsiz ağaç" diyerek ağacın yer altı ve yer üstündeki sonsuzluğunu ifade etmiștir. (Gökyay, 2006: 63)

Benzer bir inanış da Güney Sibirya Türkleri'nde görülür. Güney Sibirya Türkleri'nde ağaç, neslin devamının yanı sıra soyun yaşam güvencesini ifade eder ve bu sebepten ağacın kökünü koparmak aralarında akrabalık bağı olan kişileri ölüme terk etmek olarak görülmüştür. (Lvova, Oktyabrskaya vd. , 2013: 42) Bugün Altaylar'da, Azerbaycan'da, Balkanlar'da, Anadolu'da ve Orta Asya'da ağaca bez, beşik, bebek, kurdele ve tülbent bağlanmasının en önemli sebebi ağaçların soy kökü ile olan ilişkisi ve ağacın doğurganlık fonksiyonudur. (Bayat, 2018: 179)

Türk kültüründe genel manada ağaçlar çevresinde gelișen inanış ve ritüellerin yanı sıra bazı ağaç türlerine dair de olumlu, olumsuz bir takım inanışlar ve bu tür ağaçlar çevresinde yapılan uygulamalar mevcuttur. Örneğin Türk dünyasında kayın ağacı kutlu, mübarek bir ağaç olarak nitelendirilmiş, kerametinin olduğuna inanılmış ve kayın ağacı yanında adaklar adanıp dualar edilmiştir. Ayrıca kayın ağacından yapılmış eşyalara saygı gösterilmiştir. (Tanyu, 1975: 132-134) Kavak ağacı göğün direği olarak nitelendirilmiș ve dünya ağacı olarak görülmüștür. Ayrıca kavak ağacı bayrağın ve bağımsızlığın da bir simgesi haline gelmiştir. (Ergun, 2012: 271) Anadolu'nun birçok yerinde ardıç, mersin, selvi ve çınar ağacı gibi büyük ve eski ağaçlar koca ağaç olarak isimlendirilmiş ve bu ağaçlar kutlu sayılmıştır. Bunlar kesilmemiș, çeşitli hastalıkların tedavisinde kullanılmış, ip, bez vb. bir takım nesneler bu ağaçlara bağlanmıștır. (Roux,1994: 144) Selvi ağacı uzun boyu ve sürekli yeşil kalması sebebi ile ebedi hayatı sembolize etmiş ve genellikle mezarlıklara dikilmiştir. (Ergun, 2012: 294)

Çevresinde birtakım inanışların geliştiği ve ritüellerin görüldüğü ağaçlardan biri de kuşburnu ağacıdır. Kuşburnu her türlü iklime uyum sağlayabilen soğuğa karşs dayanıklı ve kolay yetişen bir bitkidir. Çok hızlı büyür ve gelişir. Bugün Türkiye'nin birçok yerinde, çoğunlukla da Doğu Anadolu ve İç Anadolu bölgesinde sıklıkla görülür. Cinsine göre değişmekle birlikte boyu genellikle 1-3 metredir. Çiçeği, dikeni, meyvesi ve yaprakları bulunur. Yaprakları iklimine göre mart, mayıs gibi açar, sonbahar kış gibi de dökülür. Yaprakları yeșil, çiçekleri ise pembe veya beyaz renklidir. Görünümü farklılık göstermekle birlikte meyvesi genellikle oval, kırmızı veya turuncudur ve meyvenin içinde tüylü çekirdekleri vardır. (Duman, 2014: 1-2) Yaban gülü, şillan, deli gül, gül burnu, gül elması, öküz göbeği, it burnu, fukara portakalı, kış gülü, asker gülü, it gülü, mayıs dikeni, köpek gülü olarak da isimlendirilen kuşburnu, Türk mitolojinde önemli bir yer ihtiva eder. (Öz, Baltacı, Deniz, 2018: 285286)

Kuşburnu dikenli bir ağaçtır ve Türk kültüründe erlik, şeytan, cin vb. kötü ruhların dikenli ağaçlara gelmeyeceğine dair bir inanış bulunur. Bu surette evleri şeytan ve kötü ruhlardan korumak için evlerin kapılarına kuşburnu, böğürtlen, kızıl diken vb. bitkiler asılır. Aynı şekilde nazardan korunmak için çaltı, iğde, kuşburnu gibi ağaçların dalları nazardan korunmak için takılır. Altay kahramanı Ak Tayçı'nın yaptığı gibi kahraman kişiler erlikle veya şeytanla mücadele ederken dikenli çalılar veya çubuklar kullanmaktadır. (Ergun, 2012: 401)

Kuşburnu, Altaylar'da insanlara ve hayvanlara hastalık ve felaket getiren kötü ruh Erlik'in adıyla bağdaştırılır. Altaylar gelecekte Erlik'in aç gözlülüğünü azaltmak için tayıga adını verdikleri kurbanı, 
onun korktuğu kuşburnu ağacının (togonok) ya da akdikenin (pele) yanında sunarlar. (Potapov, 2012: 32)

Eski Prusya'daki Çingeneler de çam ağacını ya da kușburnu çalısını kutsal kabul ederler. (Berger, 2000: 27) Sibirya'nın bazı kesimlerinde kötü ruhların dikenli ağaçlardan korktuğu düşünülerek evlerin önüne kuşburnu çalıları asılır. (Ergun, 2012: 402) Bilinen ilk Türkçe sözlük olan Dîvânü Lugât'it Türk'te de kuşların kötüsü saksağan, ağaçların kötüsü kuşburnu (yaban gülü), yerin kötüsü bataklık, halkın kötüsü de Barsganlılar olarak verilmiștir:

\author{
"Kuş yawuzı sagzigan \\ Yıgaç yawuzı azgan \\ Yer yawuzı kazgan \\ Budun yawuzı Barsgan" (Kâşgarlı Mahmut, 1985: 439)
}

\title{
Halk İnanışlarında Kuşburnu
}

Türk halk inanışları, Türk kültürünün önemli mevzularından biridir. "İnanç, sözlük anlamı ile kişice, ya da toplumca, bir düşüncenin, bir olgunun, bir nesnenin, bir varlığın gerçek olduğunun kabul edilmesidir." (Boratav, 1984: 7)

Halk inanışları toplum içinde kabul gören, halkın arasında yaygın șekilde varlığını sürdüren, nesilden nesile aktarılan din dışındaki inanışlardır. İnanışlar, bireylerin karşılarına çıkan çeşitli olaylar ve durumlar karşısındaki tutumlarını ve davranışlarını belirler. Bugün varlığını sürdüren pek çok inanışın kökü çok eskilere dayanır ve birçok inanış karşılaşılan kültürlerden izler taşır. (Sever, 2016: 45-51) Türk kültüründe genel manada ağaçlara ve ağaç türlerine dair çeşitli inanışlar gelişmiştir.

"Varlığın bașlangıcı ve devamında hava, su ve toprak kadar önemli bir yere sahip olan ağaç, kişioğlunun inanış ve düşünüş dünyasında türeyiş, beslenme, Tanrı ile irtibat kurma, cennete ulaşma, şifa, dilek vs. aracı rolünü üstlenmiştir. Ağacı tanrısal bir varlık olarak kabul eden insanlık onu neredeyse bütün inanma ve pratiklerinde ana eksene oturtmuştur. Ağaç dünya kültürlerinde yağmur yağdırma, güneş açtırma, sürüleri ve sığırları çoğaltma ve kadınları kolayca doğurtma gücüne sahip bir varlık olarak görülmüştür." (Ergun, 2012: 25)

Doğumdan ölüme insan yaşamının pek çok sahasında kuşburnuya dair inanışlar ve uygulamalar mevcuttur. Hamilelik ve nazarla ilgili inanışlardan, köstek kesme ve aydaşlık uygulamalarına, halk takvimine bağlı çeşitli hususlarda kuşburnu önemli bir yer ihtiva eder. Doğum ve çocukla ilgili inanışlarda kuşburnu çevresinde gelişen uygulamalara örnek olarak şunlar verebilir:

Çuvaşlar'da çocukların hastalığı çoğu zaman iye adı verilen kötü bir ruha bağlanır. Sürekli ağlayan zayıf ve çelimsiz çocuktaki iyeyi yok etmek için yumsı adı verilen kişi çağrılır. Yumsı çocuğun hastalığını iyeye bağlarsa çocuğu evin ortasına getirir ve üzerine bir örtü örter. Üzerinde bir tutam keten yakar ve kuşburnu çubuğuyla bir taraftan örtüye vururken diğer taraftan da dua okur. En son ki işlemde de çocuğu su ile yıkar. (Aça, 2008: 29)

Anadolu'nun birçok yerinde yapılan kırklama adetlerinde bebeğin doğumunun kırkıncı günü anne ve bebeğe kırk banyosu yaptırılır. Hazırlanan yıkama suyunun içine okunmuş kırk taş, kırk fasulye veya nohut, altın, para vb. nesneler atılır. Anne ve bebek bu su ile yıkanır ve yıkamadan artan su, el ayak değmedik bir yere veya bir ağaç dibine dökülür. Suyun döküldüğü ağaç cinsi de çeșitlilik gösterir ve kırklama suyu her ağacın dibine dökülmez. Bingöl'de bebeği kırklama işleminden artan su kuşburnu ağacının dibine serpilir. (Kalafat, 2017: 422)

Anadolu'nun birçok yerinde aydaş çocuğun kuşburnu dallarından geçirilirse iyileşeceğine inanılır. (Sever, 2004: 105) Bu doğrultuda Osmaniye'de kuşburnu ağacından kesilen uzun bir dalın arası bıçak yardımıyla açılır. Büyümeyen çelimsiz çocuklar iki parçaya ayrılıp çember haline getirilen dalın içinden arka arkaya üç kez geçirilir. Bu işlem üç çarşamba aynı şekilde uygulanır. (Karakaş, 2015: 161) Elazığ'da kuşburnu ağacından uzun bir dal kesilir ve dalların iki ucu ip ile bağlanır. Çember halindeki kuşburnu dalı içinden çocuğu olmayan kadınlar, kırklı çocuk ve kadınlar geçirilir. (Doğan, 2013: 124)

Erzurum'da çocuk doğduğu zaman çocuğun doğduğu evin kapısının üzerine kuşburnu çalısı asılır. Ayrıca Anadolu'da bazı yerlerde çocuğu ölen kişiler evin kapısının önüne kuşburnu çalısı asar. (Kesgin ve Özcebe, 2004: 50) 
Kuşburnuna dair bir başka inanış da kuşburnu ağacının olduğu yerde cinlerin evinin olduğuna ve cinlerin kuşburnu ağacı çevresinde toplandığına dairdir. Şebinkarahisar'da kuşburnu ağacının dibinde cinlerin yattığına inanılır ve bu sebepten geceleri bunların altında abdest bozmanın ve buralara çöp atmanın iyi olmayacağı düşünülür. (Çelik ve Kuruca, 2000: 350) Ayrıca Bingöl'de kuşburnu ağacının olduğu yerlerde cinlerin bulunduğuna inanılır. (Kalafat, 2017: 418) Pülümür'de mart ayının kara çarşamba olarak adlandırılan gününde siyah bir ip bağlanır ve bu ip kuşburnu ağacı dibine gömülür. İpe atılan her bir düğüm için dua edilir. Her sene insan ve hayvanları kötülükten korumak amacıyla bu ritüel gerçekleştirilir. İpe atılan her bir düğüm gibi karşılaşılabilecek her bir kötülügün de bağlanacağına inanılır. ( Dikme, 2018: 110)

İç Anadolu'daki bazı șehirlerde kuşburnunun dua edilerek evin eşiğine gömülmesi halinde eve bolluk bereket geleceği düşünülür.

“Zile'de Hıdırellez günü yedi adet arpa tanesine üç İhlâs, bir Fatiha suresi okunarak bir bez parçasına konulur ve kuşburnu ağacının dibine gömülür. Arpa yeșerirse o yıl bolluk ve bereket olacağı söylenir." (Yardımcı, 1999, 339)

Kuşburnu ağacı çevresinde gelişen inanışlardan bir diğeri kuşburnu dalının nazarı önlemesidir. Evlerin, ahırların ve iş yerlerinin kapılarına nazarı önlemesi için kuşburnu dalı asılır. Kuşburnunun nazarı önlediğine dair görüşlerden biri de Pervin Ergun'a aittir:

Defne, mazı, meșe, menengeç, narçiçeği, dağdağan, çitlembik, alıç, kuşburnu, iğde, akdiken, kızıl diken, karaağaç (üvez), çıtlık, böğürtlen, çıra ağacı, gül dalı; dut ağacı gibi dikenli çalılar ve ağaçların Tanrı kutu taşıdığına inanılmaktadır... Onlardan yapılan nazarlıkların da kutlu olduğu, bulunduğu yeri veya kişiyi kötülükten, kem gözlerden koruduğu inancı yaygindır. (Ergun, 2012: 399-400)

Artvin'de arpa, kömür, kiraz ağacının kabuğu ve kuşburnu dikeni üçgen biçiminde birbirine bağlanır. Bunun dışına bir parça demir ve mavi boncuk dikilerek nazar değen hayvanların alnına takılır. Ayrıca kuşburnu dikeninin kabuğu soyulur, halka şeklinde sarılır ve nazar değen kişiye verilir. (Gökçimen, 2005: 200)

Türk kültüründe ağaç, türbelerle ilgili yapılan uygulamalarda bir araç vazifesi görür. Tarih boyunca türbe kenarında bulunan ağaçlar ziyaret yeri ile ilişkilendirilmiş bazen ağaçtan türbeye bazen de türbeden ağaca bir mana yüklenmiştir. Türbelerde ağaca bez bağlanarak orada yattığı inanılan evliyanın adına dua edilmesi Şamanlık döneminden kalan kültürün izlerinden biridir. Bu bağlamda Şamanlık döneminden kalma soy ağaçları ve büyük ataların kabirleri İslamiyet'in etkisi ile makam ve türbelere dönüștürülmüştür. (Bayat, 2018: 180)

Ahmet Yaşar Ocak, ağaç yanlarında bulunan mezarlıklar ve evliyalar arasındaki ilişkiyi şu şekilde açıklamaktadır:

\begin{abstract}
"Bazı ağaçların yalnızca bir türbe yanında bulunmaları onlara kutsallık verilmesine neden olmuştur. Bu durumda ağaç yanındaki türbe gerçektir. Ağacın yanındaki mezar, zaten eskiden beri kutsal olarak kabul edilen ağacın kutsallığı ile birleşerek türbe kimliğine girebilir. Oysa başlangıçta hiçbir özelliği olmayan bir mezardır. Bazı ağaçların yanında hiç türbe olmamasına rağmen kutsal sayıldıkları görülmektedir. O halde bu durum, şöyle yorumlanabilir: ya orada eskiden bir türbe vardır ya da bir evliyanın ruhunun ağaçta yaşadığı düşünülebilir." (Ocak, 1983: 93)
\end{abstract}

Sivas Gölova'daki “Bakır Baba” türbesine giden bekâr kızlar bahtının açılması için kuşburnu ağacına herhangi bir eşyasını asarlar. (Kaya, 2002: 280) Aynı şekilde evlenmek isteyen kızlar Sivas'ın Bayırüstü Köyü ile Uzunbağ Köyleri arasındaki Yel Hüseyin ziyaretinde bulunan kuşburnu ağacına mendil bağlarlar. (Ergun, 2012: 656) Divriği'nin Kavaklısu Köyü'nde taşlarla çevrilmiş bir mezarın üzerinde çaputların bağlandığı kuşburnu ağacı bulur. (Ergun, 2012: 669) Aynı şekilde Sivas'ın Sarkışla İlçesi'ndeki "Abdal Baba" ve "Tülice Baba" türbelerinin bahçesinde kuşburnu ağacı yer almaktadır. Gelen ziyaretçiler buradaki kuşburnu ağaçlarına bez bağlayıp dilekte bulunurlar. (Gökbel, 2002: 3) Şebinkarahisar Akçakoca Mevkii'ndeki ziyarete gelen ziyaretçiler mezarın yanındaki kuşburnu ağacına ip ve çaput bağlarlar. (Bayar, 2014: 184) Erzurum'un Pasinler İlçesi Baldızı Köyü'nde bulunan Baldızı ziyaretinde ziyaretçiler mezarın yanındaki kuşburnu çalısına bez asarlar. (Ergun, 2012: 631) Sivas'ın soğuk çermik yakınlarındaki Ahmed-i Turan mezarının ön tarafında bir kuşburnu çalısı yer alır. Ziyarete gelenler bu kuşburnu çalısına dileklerine göre bez, çamaşır, saç, kurdele, ip vb. nesneleri adak olarak bağlarlar. (Bulut, 2011: 132) Ylldızeli İlçesi'nin 
Banaz Köyü'nde Pir Sultan Abdal heykelinin olduğu yer kutsal olarak nitelendirilir, heykelin sağında ve solunda yer alan kuşburnu ağaçları dilek ağacı vazifesi görür. Ayrıca bu köyde Pir Sultan'ın küçük oğlu Seyyid Ali'nin yatırı olduğuna inanılmaktadır. Bu yatırın çevresinde de çaputların bağlandığı bir kuşburnu ağacı bulunmaktadır. (Ergun, 2012: 979).

Kuşburnu ile ilgili bir başka inanış halk takvimlerinde görülmektedir. Ankara'nın Türkmen Köyü'nde kuşburnunun çok olduğu seneler kışın uzun süreceğine inanılır. (Arslan, 2006: 7) Aynı inanış Pülümür ve çevresinde de mevcuttur. (Dikme, 2018: 106). Bayburt'ta kuşburnunun çok olduğu sene o yıl kışın sert geçeceğine ve karın çok yağacağına dair bir inanış vardır (KK.7) Zile'de kuşburnunun bol olduğu sene kışın çetin geçeceğine inanılır. (Sezmiş, 2018: 75)

\section{Halk Hekimliğinde Kuşburnu}

Halk hekimliği ve geleneksel tıp doğa olayları karşısında ilk insanın takındığı tavırlardan oluşmuştur. İnsanoğlu ortaya çıktığı ilk günden itibaren ruhsal ve bedensel bir takım hastalıklarla karşı karşıya kalmış, ilk insanlar bedenlerinde ve ruhlarında beliren hastalıkların ortaya çıkış sebeplerini ve bunlara çare olacak tedavi yöntemlerini aramaya çalışmıştır. Tabiat olaylarından kaynaklanan hastalıkların tedavisinde yine tabiattan istifade etmişler çeşitli ağaç ve bitkileri kullanmışlardır. Hastalıkların bitkilerle olan tedavisi antik çağlara dayanmaktadır. Aynı şekilde Anadolu'da bitkilerin çeşitli hastalıklarda kullanımı Hititlere uzanmaktadır. (Avcıoğlu, 2017: 13, 17) Halk hekimliği, "halkın olanakları bulunmadığı için ya da başka sebeplerle doktora gidemeyince veya gitmek istemeyince hastalıklarını tanıma ve sağaltma amacı ile başvurduğu yöntem ve işlemlerin tümüdür." (Boratav, 1984: 113).

Ağaçlar ve bitkiler halk inanışları ve halk hekimliği çerçevesinde farklı şekillerde kullanılır. Ağacın kendisi kadar yaprakları, tohumu, meyvesi, dalı hatta kökü bile önemlidir. Şifa verdiğine inanılan ağaçların kökü, dalı, yaprakları ve meyveleri kaynatılır veya demlenir. Bunlar şifa amaçlı, dâhili ve harici olarak kullanılır. Kuşburnu ağacı tek başına çok sayıda inanışı yansıtmasının yanı sıra kuşburnu; meyveleri, dikeni, dalı ve çiçeği ile de Türk kültüründe farklı anlamlar taşımaktadır. Ayrıca kuşburnunun meyveleri kaynatılarak veya ezilerek halk hekimliği sağaltmalarında kullanılır.

Kuşburnu Hipokrat zamanında iltihaplara karşı, Orta Çağ'da da kan tükürmelerine, diş eti kanamalarına, tenyaya, ishale ve yılancığa karşı kullanılmıştır. (Akçiçek, 1997: 173)

İbn-i Sina, kuşburnuyu köpek böğürtleni olarak isimlendirmiş ve kabız etkisi yaratmasından dolayı kanlı basurda ve ishalde, yapraklarından hazırlanan çayın ise kızarıklık ve kaşıntılarda kullanıldığını belirtmiştir. Kuşburnu, Osmanlı döneminde idrar sökücü olarak kullanılmıştır. İlk ilaç formül kitaplarından olan Düstur al-Edviye'de de kuşburnu yer almıştır. (Şar, 2011: 5) Günümüzde şifa veren yanıyla dikkatleri çeken ve aktarların özellikle soğuk kış günlerinde çokça sattıkları kuşburnu rengi, tadı ve kokusuyla pek çok kişi tarafından tercih edilmektedir.

Kuşburnu halk hekimliğinde ishal tedavisinde, mesane ve safra taşlarının düşürülmesinde, diş eti kanamalarında, kan şekerinin düşürülmesinde ve hemoroid (basur) rahatsızlıklarında kullanılır. Kaynatılıp içildiğinde mayasıla da iyi geldiği söylenmektedir. (Sever, 2004: 105) Ayrıca soğuk algınlığı, öksürük, nefes darlığı, grip gibi solunum yolları hastalıklarında alternatif tedavi olarak sıklıkla tercih edilir. Hastalığın çeşidine göre kullanımı değişir. Kimi durumlarda dâhili kimi durumlarda ise harici biçimde kullanılır. Örneğin ishal durumunda kuşburnunun suyu içilir, ezmesi ve reçeli yenir. Hemoroid durumunda ise hem dâhili hem de harici olarak kullanılır. Kuşburnu kaynatılıp suyu içildiği gibi kuşburnu ezmesi hemoroidli bölgeye sürülür. (Akçiçek, 1997: 175)

Bingöl'de kuşburnu, soğuk algınlığının tedavisinde kullanılır. Dokulardaki sertliklere ve kemik erimesine iyi gelir. Ateşi düşürür, yorgunluğu geçirir ve bağışıklık sistemini güçlendirir. Bağırsak hastalıklarını iyileștirir. Safra kesesinde taş oluşumu engeller. Karaciğer iltihabını giderdiği ve tansiyonu düzenlediği de söylenmektedir. (Irmak, 2018: 60)

Kuşburnu yağı Hatay ve çevresinde romatizma için kullanılır. Ağrıyan bölgeye masaj yapılarak kuşburnu yağı sürülür. Ayrıca Zona hastalığı için de kuşburnundan yararlanılır. Dört bardak suya dört kaşık ezilmiş kuşburnu konulur, otuz dakika kadar kaynatılır ve günde üç defa içilir. (Arı ve Top, 2017: 62-63)

Sivas'ta kısır olan kişiler için kuşburnu ve fındık yağlarından bir karışım hazırlanır. Kastamonu'da kuşburnunun tohumu her türlü iç hastalıklarının tedavisinde kullanılır. Sivas'ta kuşburnunun kökü bakır kap içinde yakılır ve külü cilt hastalıklarında kullanılır. Ayrıca demre veya derma olarak bilinen 
yaraların üzerine kuşburnu suyu sürülür. Malatya'da mantar ve saçkıran gibi rahatsızlıklarda kuşburnunun bir dalı yakılır, bundan damlayan sıvıyla yaraya merhem yapılır. Van'da vücuttaki kaşıntıları gidermek için kuşburnunun çiçeği ezilir ve kaşınan bölgeye sürülür. (Akçiçek, 1997: 174)

Şebinkarahisar'da da kuşburnu suyu kısırlık tedavisinde kullanılır. (Avcıoğlu, 2017: 141) Ayrıca kan dolaşımını düzenlemek, böbrek taşını düşürmek, basur şikâyetlerini azaltmak, kabızlıktan kurtulmak, ödem atmak, saçkıranı tedavi etmek, nezle ve gripten kurtulmak için de kuşburnu meyvesinden yararlanılır. (Avcıoğlu, 2017: 51, 64, 70, 93, 97, 137) Mersin'de astım ve bronşit tedavisinde, böbrek hastalıklarında kuşburnu kullanılır. (Sever, 2016: 171,184) Kayseri'de kuşburnu yaban gülü olarak isimlendirilir ve ishali durdurmak için kuşburnu tohumu ezilir, kaynatılır ve aç karnına içilir. Aynı tedavi safra kesesi taşları ve iltihapları için de uygulanmaktadır. (Yağmur, 1996: 132, 146) Trabzon'da soğuk algınlığı ve nezle tedavisinde, mide ağrılarında, bağırsak rahatsızlıklarında kuşburnu çeşitli şekillerde dâhili ve harici olarak kullanılır. (Baysal, 2014: 146, $148,154,163$,) Kars ve Iğdır'da baş ve böbrek ağrılarını, idrar yolları enfeksiyonunu, öksürüğü ve bronşiti geçirmek için kuşburnu meyvesi kaynatılıp içilir. Ayrıca hemoroid için kırmızı kuşburnu çayı tüketilir veya kuşburnu meyvesi ezilip içine zeytinyağı konulur. Hazırlanan karışım hemoroidli bölgeye sürülür. (Öncül, 2011: 15, 24, 47,57, 59) Pülümür'de öksürüğü azaltmak için kuşburnunun kökü çıkarılır, kaynatılarak içilir. (Dikme, 2018: 115) Niğde halk hekimliğinde kansızlığa karşı kuşburnu tüketilir. (Çolak, 2015: 58)

Bayburt'ta lohusa kadınlara sütünün artması için kuşburnu suyu içirilir. (KK.7) Tosya'da yeni doğum yapan kadınların sütünü artırmak için kuşburnu haşlanıp elekten geçirilir ve unla pişirilir. Tıraş adı verilen bu lohusa tatlısı ile lohusa kadınların sütü çoğalır. (Karabüber, 2017: 57)

Ankara Kazan'da da siğil ocakları bulunur. Burada siğil üzerine kuşburnu ve iğde çalısından bir dal koparılır. Onun dikeni ile siğilin üzeri üç İhlas okuyarak çizilir. Bu dallar güneş görmeyen bir yerde saklanır. Dallar kuruyunca siğilin de kuruyacağına inanılır. (Begiç, 2013: 290) Aynı şekilde Kızılcahamam'ın Süleler Köyü'nde siğili tedavi ettiği inanılan bir kuşburnu ağacı bulunmaktadır. Vücudunda siğil olanlar buradaki kuşburnu ağacına giderken ve dönerken kimseyle konuşmaz ardından kuşburnu dallarından kırar ve arkasına bakmadan oradan ayrılır. Dalların kurudukça siğilin de kuruyacağına inanılır. (Ergun, 2012, 943) Çubuk'ta da siğil ocakları siğili tedavi etmek için kuşburnu ağacından yararlanılır. Bazı ocaklar kuşburnu dalını kırıp üzerine taş koyar. Dalla birlikte siğilin de kuruyacağı düşünülür. Bazı ocaklar da kesilen kuşburnu dalına siğil sayısınca dua okuyarak ve dala çentik atarak siğili tedavi etmektedir. (Özkan, 2012: 141) Aynı şekilde Zile'de siğili yok etmek için kuşburnu dalından koparılır kimse görmeden siğil sayısı kadar dala çizik atılır, dal kururken siğillerin de kuruyacağı söylenir. (Sezmiș, 2018: 86) Siğilin kuşburnu ağacı ile tedavi edilmesinin sebebi kuşburnu meyvesi ile siğil arasındaki benzerlik ilişkisidir. Siğil sayısı kadar kuşburnu dalına çizik veya çentik atılması gerçekleştirilmesi arzulanan olayın temsili içindir. (Özkan, 2012: 144) Sivas Divriği Uluçayır Köyü'nde de kuşburnu çalılarından oluşan bir ziyaret yeri vardır. Buraya siğili olan çocuklar getirilir, çocuğun siğili sayısınca dal bükülür. (Ergun, 2012: 360)

Pülümür'de bazı hastalıkları tedavi etmek için kuşburnuna çekme adı verilen bir tedavi yöntemi uygulanır. Buna göre biri hasta olduğunda topluluktaki yaşlı veya keramet ehli kişi kuşburnu ağacından bir dal koparır. Bu dalı ortadan ayırarak bir çember haline getirir. Hastanın kafasından geçirilen çember vücudunda dolaştırıldıktan sonra sağ ayağından çıkarılır. Bu işlem üç kez üst üste tekrarlanır. İşlem sonunda dal kırılıp siyah bir ipe bağlanır ve ahıra asılır. Bu tedavi yöntemine kuşburnuna çekme adı verilir. (Dikme, 2018: 113-114)

Sivas'ın Eğnir (Kadriye) Köyü’ndeki sarılık pınarında hasta kişi yıkandıktan sonra elbisesinden koparılan bir parça oradaki kuşburnu çalısına bağlanır, böylece kişi hastalıktan arınır. (Akçiçek, 1997: 174) Ayrıca kuşburnunun içinde bulunan bileşenler vücuttaki yağın erimesine yardımcı olduğu için kuşburnu diyet programlarında yer almakta ve zayıflamak amacıyla da kullanılmaktadır.

Yozgat Akdağmadeni'nde "Koca Fakî” olarak adlandırılan yerde gür bir şekilde çıkıış kuşburnu ağacı bulunmaktadır, bu ağaç da yine dilek ağacı olarak kullanılmaktadır. Bu ağaca çocukları ölenler, çocuklarının yaşaması için yeni doğmuş bebeklerini getirip bu yeri sözde satarlar. Bunu yaparken de "ya al, ya ver" derler ve adakta bulunurlar. Ayrıca felç olmuşları, konuşamayanları şifa bulması için kuşburnu ağacına getirirler ve buradaki ağaca mutlaka bez asarlar. (Tanyu, 1973: 71) 
Ankara'nın Haymana İlçesi'nde Seyran Hamamı'nın bulunduğu yerde bir ziyaret yer alır. Hamama gelen kişiler hastalıklarından kurulmak için buradaki kuşburnu çalısına bez bağlar. (Ergun, 2012: 1023) Çocuğu olmayan kadınlar Kayseri'nin Ulupınar Köyü'ndeki Meryem Ana ziyaretine giderler. Ziyaretin önünde bulunan sudan içtikten suyun yanındaki kuşburnu ağacına bez bağlarlar. (Ergun, 2012: 344) Çocuk sahibi olmak isteyenler sütü gelmeyen kadınlar ,"Coban Baba" ve "Bakır Baba" mezarları yanındaki kuşburnu ağacına çaput asarlar. (Kaya, 2002: 280)

\section{Halk Edebiyatı Ürünlerinde Kuşburnu}

Kuşburnu çeşitli şekillerde halk edebiyatı ürünlerinde kullanılmıştır. Kuşburnu üzerine türküler söylenmiş, maniler yakılmış, efsaneler anlatılmıştır. Halk şairleri kuşburnunu ve kuşburnundan yapılan yiyecekleri şiirlerinde dile getirmiştir. Bayburt'ta kuşburnu püresi kokoç olarak adlandırılır. Kokoçtan tatlı çorba veya kokoç çorbası olarak adlandırılan çorba yapılır. (KK.1) Kuşburnu ve bundan yapılan yiyecekler Bayburtlu halk şairlerinin şiirlerinde sıkça yer almıştır.

\section{Kokoç Çorbası (Mustafa Kayalı)}

Bayburt'umda tatlı çorba adına,

Namı diğer, denir kokoç çorbası.

Her gelen misafir bayram tadına,

Varsın diye, konur kokoç çorbası.

Soğuğa bire bir, mahalli icat

Doktora, ilaca gayri ne hacet!

Desem! Her illete olursun necat

Buna, kim inanır? Kokoç çorbası.

Kayalı bunu her türlü mikroba,

Karşı içip; aslan varı kükre be.

Hoşafla bağı var. Her hal akraba,

Aşureyle dünür, kokoç çorbası. (KK.1)

\section{Yemek Destanı (Bayburtlu Celali)}

$\ldots$

Erişte çorbası, kadı dolması

Kokoç reçeliyle, emül dolması

Yine imam olmuş kelem dolması

El göğüste kalktık divan eyledik (Dursun, 2008: 209)

Bayburt'un Kışları (Mahmut Kırtan)

$\cdots$

Sarmusag, aşotu, reyhanın hani?

Dadlı çorba için kokoçun hani?

Erişten, lazutun, iç yağın hani?

Gadaşım güz geldi külür aldın mı? (Dursun, 2008: 263)

...

Bu Sofrada (Şaşkuni Baba) 


\section{Kokoç çorba derde deva}

İcenlere olsun şifa

Azimet bey eyle dua

Kurduğumuz bu sofrada (Aker, ty. : 68)

...

\section{Atışma (Mustafa Kayalı)}

...

Kokoç çorbasıyla doldur tasını

Her derde deva iç, gör şifasını

Çekildiyse getir tel helvasını

Besmeleyle biri dilse de yesek. (KK.1)

...

\section{Bayburtluca (Mahmut Kırtan)}

...

Lazut da misırdur, pürcükli havuç,

Lahana kelemdür, koşalar avuç

Kuşburnu toplanır yapılır kokoç

Galburi, kasnaği, dibegi tani. (Kırtan, 1991: 14)

Türküler, anonim halk edebiyatı nazım türlerin biridir. Așk, gurbet, ayrılık, memleket sevgisi ve birçok konuda ve belli bir ezgi ile söylenir. Türküler Anadolu insanının acılarını, sevinçlerini, özlemlerini yansıtır. Ait olduğu coğrafyanın ve kültürün izlerini taşır. Kuşburnu üzerine tespit ettiğimiz beş türkü mevcuttur. Bunlardan ikisi Bayburt'a, diğerleri Sinop, Yozgat ve Sivas'a aittir.

Kuşburnunun kurusu tarinnam

Geçti kızlar sürüsü tarinnam

Sürüsünde fayda yok tarinnam

İçlerinden birisi tarinnam

$\ldots$

Kuşburnunun alından tarinnam

Koparırlar dalından tarinnam

Kızlar zekat vermiyor tarinnam

Babasınin malından tarinnam

-..

Kuşburnu çiçek açtı tarinnam

Köyünden bir kız kaçtı tarinnam

Bir daha var kaçacak tarinnam

Ne aralar açacak tarinnam (Tan ve Turhan, 1997: 64)

$\ldots$

Bayburt'a özgü diğer bir türkü de "Kuşburnu Derde Derman" türküsüdür:

Kuşburnu derde derman 
Çok geldi geçti kervan

Az verdim çok yalvardım

Olmadı derman haydi

Ağam haydi paşam haydi

Kunduram taştan kaydı

Elin bir tanesine de

Nasil diyeyim haydi

Kuşburnu pürlenir mi?

Dibi süpürlenir mi?

Bayburt'tan yâr sevenin

Yakası kirlenir mi?

Ağam haydi pașam haydi

Kunduram taştan kaydı

Elin bir tanesine de

Nasil diyeyim haydi (URL-1)

Yozgat Akdağmadeni yöresinde "Kuşburnuyu Budarlar" türküsü söylenir:

Kuşburnuyu budarlar

(Hoydah) Işkın sürmesin deyi

Bizi burdan koğarlar

(Hoydah) Güzel sevmesin deyi(Akçiçek, 1997: 176)

Sinop Boyabat yöresinde "Derelerde Kuşburnu" türküsü bilinir:

Derelerde guşburnu

Guşburnuyu guş yir mi?

Nirinna nirinah nirinna niya ha ha

Nirinna nirinah nirinna niya ha ha (TRT, 2006: 274)

Sivas çevresinde de kuşburnu türküsü söylenmektedir:

Kuşburnular bayırlarda gül gibi

Hevenk olmuş çiçekleri kor gibi

Türlü otlar sofradaki nar gibi

Nane bizim reyhan bizim har bizim

Karpuz nane sofradaki bal bizim (Kuzucular, 1978: 24)

Türk halk edebiyatında meyveler, çiçekler ve ağaçlar üzerine söylenmiş çok sayıda mani vardır. Kuşburnu da bu mani örnekleri içinde yer alır:

Kuşburnu çiçeklendi 
Bar verdi gerçeklendi

Biz ayrılık bilmezdik

Ayrıllk gerçeklendi (Emir, 1987: 11)

***

Bahçelerde kuşburnu

Oldum sevda düşünü

Kalmışıım kapınızda

Yalın ayak kış günü (Emir, 1987: 17)

***

Ay doğmuş sini gibi

Íkindi günü gibi

Ne olmuş bu yârime

Kuşburnu gülü gibi (KK.1)

Kuşburnu güllenir mi?

Dibi gübürlenir mi?

Sevdiğim oğlanın

Mendili kirlenir mi? (KK.1)

***

Kuşburnun kurusu

Geçti güzel sürüsü

Sürüsünden fayda yok

Yaktı beni birisi (Akçiçek, 1997: 176)

Karşı dağda kuşburnu

Meyve verir kış günü

Hiç ayrllık olur mu?

Zemheri ayl, kış günü (KK.2)

Kuşburnu kurutmadım

Yar seni unutmadim

Yar askere giderken

Gözyaşı kurutmadım (KK.2)

Kușburnu dikeniyim

Dibine döküleyim

Güzel gelsin koklasın

Çirkine tükeneyim (KK.3) 
Yar seni unutmadım

Saydım gül hatırını

Üstünde yâr tutmadım (Demiray, 1976: 16)

Kuşburnu pürlenir mi?

Dibi gübürlenir mi?

Keskin'den kız alanın

Mendili kirlenir mi? (Karakuş, 2006: 21)

It burnunun alına

Mendil serdim dalına

Öyle yâr kurban olsun

Ayağımın yoluna (Karakuş, 2006: 47)

Sivik ucu kuşburni

Oldum yârin düşküni

Başaçık yalınayak

Yola düştüm kış güni (Kılıç, 2012: 27)

Kușburnunun bilmece türünde verilmiș örnekleri de mevcuttur:

*Ağaç başında kırmızı mendil. (Kurtuluş, 2010: 22)

*Dışı kadife içi diken (Balcıoğlu,1951: 414)

*Küçücük küpecik

Ağzı kapacık (Sevindirici, 1986: 74)

*Aldır abası

Yeşildir küpesi

Bunu bilmeyen

Eşek sıpası (Acar, 1976: 20)

*Vurdum indirdim harka, içi kavurga (Okutan, 1949: 344)

Kuşburnu Anadolu'da yaban gülü olarak da bilinir ve yaban gülü, bülbül ile güle dair anlatılarda sıkça karşımıza çıkar. Kuşburnu ve yaban gülü efsaneleri dilden dile nesilden nesile aktarılarak günümüze kadar gelmiştir:

Bundan yıllar önce bir köyde zengin bir kız, fakir bir oğlana sevdalanmış. Oğlan da onu sevmiș. Ailesini kızı istemeye göndermiş fakat kızın babası vermemiş. Oğlanla kız gizlice görüşüp kaçmaya karar vermişler. Kız:

-Ben babamin atlarından ve parasindan alırım. Sen beni bizim tarlanın orada bekle, tamam mı? Demiş. Oğlan da:

- Tamam, demiș.

Kız bir gece babasından bin kuruş ve iki at çalarak yola koyulmuş. Tarlaya geldiğinde oğlan tarla sürüyormuş. Kız ile ilgilenmemiş. Bunu gören kız şöyle demiş:

Gel gidelim ağam oğlan

Kolum yastık saçım yorgan

Gel gidelim ağam oğlan 
Oğlan cevap vermiş:

Tohumu attım tarlaya

Başladım tarla sürmeye

Git gelemem Türkmen kızı

Kız üzülmüş, kırılmış oğlana:

Tohumunu kuşlar yesin

Sapanını kurtlar kırsın

Gel gidelim ağam oğlan

Bu sırada oğlanın içine bir korku düşmüș. O da atına binip kızın ardı sıra gitmiş. Bakmış ki kız kendini uçurumdan atmış. Dayanamamış, oğlan da kendini aşağıya atmış. Bunları bulanlar onları oldukları yere defnetmiş. O güne kadar yeryüzünde olmayan kuşburnu, bu iki sevdalının mezarı arasında büyümüș ve yeryüzüne yayılmış. (Emir, 2009: 98-99)

Söz konusunu efsanede kuşburnu ağacının yeryüzünde ortaya çıkması anlatılır. Kuşburnu ağacı efsanede kavuşamayan iki genci temsil eder. Zengin kız ile fakir oğlan birbirine sevdalanır. Oğlan kızı ailesinden istetir fakat kızın babası kızı vermez. İki sevdalı kaçmaya karar verir. Kız babasının atını ve bir miktar parasını da alarak oğlanın yanına gelir. Oğlan, kız ile ilgilenmez. Kız bu duruma çok üzülür ve kendini uçurumdan atar. Oğlan da arkasından atlar. İkisinin mezarının olduğu yerde bir kuşburnu ağacı çıkar. Böylece kuşburnu ağacı yeryüzünde yayılmaya başlar.

Diğer bir efsane örneği de kuşburnunun dikenli olmasına dairdir. Söz konusu efsanede kuşburnu yaban gülü olarak geçmektedir:

“Günlerden bir gün dünyada bitkiler ve hayvanlar yaratılmış. Sonraki gün onlara giyim kuşam verilmiş. Bütün bitkiler kendileri için gerekli olan çiçek, yaprak ve yün giysileri almışlar. Her türlü kurt-kuş çeşitli renklerde tüylere bürünmüşler. Gün geceye dönünce de bütün hayvanlar mevcut renklerini almışlar. Yalnızca yaban gülü ve bülbül bir șey almamış. Sonrasında da ikisine tek bir şık klyafet kalmış. Giysi çok güzelmiş fakat geceyi kim uyumadan geçirirse elbiseyi o alacakmış. Bülbül:

-Dünyada en güzel sesli kuş benim, en güzel elbise de benim olmall, demiş.

Yaban gülü onun böbürlenmesinden hoşlanmamış ve tepki vermiş:

-Hangimiz olur belli olmaz, belki bana senden daha çok yakışır.

Bülbül de:

-Sen bütün gece uyursun ama ben uyumam tüm gece öterim. Böylece elbiseyi ben alırım diye övünmüş.

Ardından gece olmuş, bülbül tüm gece ötmüş. Kıskançlığından gözünü kırpmadan sabaha kadar beklemiș fakat güneș doğmaya yakın bir yel ona dokunmuș ve çok yorulan bülbülün gözleri kapanıvermiş. Gözlerini açtığında ise yaban gülünün hoş kokulu pembe çiçeklere büründüğünü görmüş. Yaban gülüne olan kini artmış ve ona olan öfkesini göstermiş:

-Yaban gülü ne kadar güzel ve hoş kokulu olsan da hiçbir zaman sana konmam. Gülün dökülünce de seni it çubuğu diye adlandırsınlar, demiş.

Bülbülün yaban gülüne kini o kadar çokmuş ki bütün kinini bir şarklyla yaban gülüne dökmüş. Onun her kini yaban gülünün dallarına iğne olarak batarmış. Bir süre sonra yaban gülünün tüm çiçekleri dökülmüş, baştan aşağı dikenle kalıvermiş. Bülbül de o zamandan sonra geceleri acı acı ötüp uyumaz, yabangülünün elbisesini giyinmek için her yaz onun çiçek açmasını beklermiş. Tüm gece ne kadar uyumasa da tatlı bir yel gelince dayanamaz, gözleri kapanıverirmiş.

Bundan dolayı insanlı tan vaktinden önceki uykuya ve çok çabuk uykuya dalan çocuğun uykusuna bülbül uykusu der. Bülbülün bu uykusunu firsat bilen yaban gülü allı güllü elbisesini giyermiş. Onun bu güzelliği karşısında bülbül ona hayran olmaktan kendini alamazmış ama diğer taraftan da yaban gülüne konmama sözünü ve ona olan kinini hatırlarmış. Bu sebepten de bülbül ona uzaktan âşıkmış.

O vakitten sonra yabangülünün çalısı da kendisi de çok dikenli kalmış. Günümüzde çocukların elma bahçesine girmemesi için bahçenin kenarına yabangülü dikilir. Estetik 
görünümü yanında dikenleri ile de tel görevi görür. O sadece bir yaban gülü değil aynı zamanda bir it çubuğudur." (Atnur, 2002: 703-705)

Bu efsane Gülhan Atnur'un "Başkurt ve Tatar Efsaneleri Üzerine Karşılaştırmalı Motif Çalışması" isimli doktora tezinden alınmış bir Tatar efsanedir. Atnur bu efsaneyi etiolojik ve eskatolojik efsaneler başlı̆̆ı altında incelemiştir. Efsanede dünyadaki canlılar yaratıldıktan sonra onlara giysi verilir. Herkes kıyafetini alır fakat yaban gülü ve bülbül bekledikleri için onlara sadece bir tane elbise kalır. Bülbül ile yaban gülü "kim geceyi uyumadan geçirirse elbise onun olacak" diye bir aralarında anlaşırlar ve bu konuda iddialaşırlar. Bülbül güneş ağarıncaya kadar öter fakat dayanamaz ve uyuya kalır. Böylece giysi yaban gülünün olur. Bülbül yaban gülünün güzelliğini görünce onu kıskanır. Bülbülün kini birer diken olup yabangülünün üzerine batar ve yaban gülü artık dikenli olur. Bülbül ötmekten sararıp solar. Her yaz giysinin kendine geçmesini bekler fakat her seferinde uyuyakaldığ için bir türlü elbiseye kavuşmaz. (Atnur, 2002: 86) Buradaki efsane gülün menşeine dairdir. Efsanede yaban gülü sabaha kadar uykusuz kalıp en güzel elbiseleri giyer fakat bülbülün kıskançlığı ve kini yaban gülünün dikenli olmasına neden olur. (Atnur, 2002: 196)

\section{Mutfak Kültüründe Kuşburnu}

Kuşburnu çok amaçlı kullanım alanı olan bir meyvedir. Şifa verici özelliğinin yanı sıra mayhoş tadı ve aromatik lezzeti ile mutfaklarda yerini almıştır. Kuşburnundan yapılan birçok yiyecek mevcuttur. Özellikle kışın soğuk günlerinde çayı tüketilir. Bunun dışında meyve suyu, konsantresi, kompostası içecek olarak yapılır. Ezmesi, marmelatı ve reçeli sabah kahvaltılarında tüketilir.

Kușburnu içerikli yiyecekler farklı șekillerde isimlendirilir. Çorum'da kușburnu marmelatına "pevrede" denir. Samsun'un Havza İlçesi'nde kuşburnun ezmesi yapılır. (Özdemir, 2009: 199) Halk hekimliği bölümünde söz edildiği gibi bazı şehirlerde kuşburnunun yağı çıkarılır ve çeşitli amaçlarla kullanılır. Kuşburnundan elde edilen ürünlerden biri de kuşburnu sirkesidir. Sivas'ta "karaş" adı verilen ve kuşburnu dışında vişne ve karamuktan yapılan bir çeşit tatlı vardır. (KK.5)

Kuşburnu Bayburt'ta tüketilen önemli besinlerden biridir. Sonbahar ayı geldiğinde Bayburt'ta kuşburnu toplama işi başlar. Pazarlarda kuşburnu satılır, çeşit çeşit kuşburnu marmelatı ve püreleri yapılır, şarküterilerin raflarını süsler. Kadınlar bin bir zahmetle kuşburnunu toplar, bunları kurutur. Kokoç adı verilen tekerlek biçiminde pestiller yapılır. Yapılan bu işlemler kış ve özel günler için bir hazırlıktır. (KK.7)

Bayburt ve Erzurum'da kuşburnundan kokoç çorbası pişirilir. Kokoç çorbası özellikle Bayburt mutfağının en önemli tatlarından biridir. Çorba deyince ilk olarak sıcak ve tuzlu içecek gelir fakat Bayburt'a özgü olan kuşburnu çorbası klasik anlamdaki çorbalardan biraz daha farklıdır. Soğuk olarak ve üzerine bolca findık eklenerek servis edilir. Temel malzemesini kuşburnudur. Bununla birlikte içine gendime (yarma), üzüm, kayısı, erik veya incir kurusu katılır. (KK.3, KK.5, KK.7)

Bayburt halkının tatlı çorba veya kokoç çorbası olarak isimlendirdikleri bu yemek, bir çeşit aşureye benzer. Bayburt'a memur olarak veya çeşitli sebeplerden gelen insanlar tatlı çorbayı duyunca ilk etapta şaşırırlar fakat onun eşsiz lezzetini tadınca birçok kişi için vazgeçilmez olur.

Tatlı çorba genellikle bayram, düğün, aşure günlerinde ve ramazan ayında yapılmaktadır. Özellikle sıcak Ramazan günlerinde, iftar sonrasında müthiş bir serinlik ve enerji vermektedir. Kuşburnu çorbası Bayburt' da bayramların olmazsa olmazıdır. Bu adet öylesine içselleşmiştir ki aileler çeşitli sebeplerden Bayburt dışına yerleşseler bile kuşburnu çorbası bayramlarda baş ikramdır. Bayramlarda yaprak sarmasının, kıymalı tarhunlu böreğin yanında kuşburnu çorbası da ikram edilir. Bayburtlu kadınlar aşure gününde klasik aşure dışında tatlı çorba yapıp komşularına dağıtırlar. (KK.7)

Erzurum'da kuşburnunun tiridi yapılır. Haşlanan kuşburnu ezilir ve süzgeçten geçirilir. Kuru kayısı ve kuru üzüm konulur ve birlikte kaynatılır. Kaynayan karışıma şeker ilave edilir. Servis tabağına ekmek doğranır. Kuşburnu karışımı ekmeğin üzerine dökülür. Üzerine de tereyağı eritilip servis edilir. (KK.5)

Kuşburnu bu fonksiyonlarını dışında günümüzde besin ve ilaç sektöründeki birçok ürünün yapımında da kullanılmaktadır. Poşet çayından marmelatına, meyve suyundan meyve jölelerine, bebek gıdalarından, pasta ve şekerleme sanayisine kadar birçok alanda kuşburnu yer alır. Bu 
doğrultuda Gümüșhane, Amasya, Tokat, Çorum gibi şehirlerde kușburnu fabrikaları bulunmaktadır. Ayrıca kök boyacılıkta kırmızı rengi vermek için de kuşburnundan yararlanılır. (Akçiçek, 1997: 173)

Kültür Turizm Bakanlığı arşivine Gümüşhane adına tescil ettirilmiş bir de kuşburnu düdüğü bulunmaktadır. Mahmut Polat, kuşburnu ağacından bir tür nefesli çalgı aleti yaparak Gümüşhane Kelkit'te bir asır önce bilinen ve unutulmuş olan kuşburnu düdüğünü 2010 yılında Türk kültürüne yeniden kazandırmıștır. Kuşburnu pek çok alanda sağladığı faydaları ile her geçen gün kıymetini artırmaktadır. Gümüşhane'de her yıl ağustos ayı içerisinde Kuşburnu-Pestil Kültür ve Turizm Festivali düzenlenmektedir. (KK.6)

\section{Sonuç}

Kuşburnu, Anadolu coğrafyası ve Türk dünyasında olumlu ve olumsuz yönleriyle karşımıza çıkan bir ağaç türüdür. Dîvânü Lugât'it Türk'te ağaçların kötüsü olarak nitelendirilmiştir. Dikenli bir ağaçtır ve Türk mitolojisinde dikenli ağaçlara yüklenen bir fonksiyon vardır. Altaylar'da ve Sibirya'da kötü ruhları korkutmada kuşburnu çalısı kullanılır.

Kuşburnu özellikle İç Anadolu ve Doğu Anadolu bölgesinde çok yetişen bir ağaç türüdür. Söz konusu bu bölgelerin iklim ve bitki örtüsü türü kuşburnu ağacının yetişmesine elverişlidir. Buna bağlı olarak bu bölgelerde halk arasındaki inanışları ve işlevleri de çok fazladır. Nazara ve kötü ruhların zararlarına karşı kuşburnu ağacı çevresinde ritüeller gelişirken bolluk ve bereketi artırmak, halk takvimini belirlemek, aydaş çocukları yürütmek için de kuşburnuna dair çeşitli uygulamalar gerçekleşmektedir. 0 aroması ve tadı ile bir taraftan Türk mutfağını süslerken diğer taraftan çayı, püresi, yağı ve sirkesi ile çeşitli hastalıklara şifa vererek alternatif tıpta yerini almıştır.

Kuşburnu sözlü halk edebiyatı ürünlerinde de karşımıza çıkmaktadır. Kuşburnu ağacı, meyvesi ve ürünleri hakkında âşıklar şiirler icra etmişlerdir. Bu konuda türküler söylemiş ve maniler düzülmüştür. Ayrıca kuşburnu üzerine tespit edebildiğimiz iki tane efsane bulunmaktadır.

Kuşburnunun çeşitli sektörlerde kullanımı her geçen gün artmaktadır. Kuşburnu genellikle kendi kendine yetişen, özel bir emek gerektirmeyen bir ağaç türü olduğu için kolaylıkla yetiştirilebilir. Günümüzde çok çeşitli sektörlerde kullanılan kuşburnunun ürün çeşitliliği artırılabilir. Bu sayede milli servete katkı sağlamanın yanı sıra açılacak fabrikalarda çok sayıda insan istihdam edilir.

\section{Kaynakça}

Acar, İ. H. (1976). Bilmece bildirmece, Sivas: Emek Matbaası.

Aça, M. (2008). Trabzon-Şalpazarı Çepnileri ile Çuvaş Türklerinin doğum sonrası etrafındaki inanış ve uygulamaları üzerine bir karşılaştırma denemesi. Karadeniz, Y: 1, S. 1, 21-34.

Akçiçek, E. (1997). Eren'ce halk bilim yazıları. İzmir: Güneşim Ofset.

Aker, A. U. (Tarihsiz). Hicranı anlayan şehir, Bayburt: Özer Ofset.

Arı, B. ve Top M. B. (2017). Hatay'da sağlık sorunlarını gidermek için başvurulan başlıca halk hekimliği uygulamaları. Karadeniz, S.33, 55-67.

Arslan, A. (2006). Ankara Türkmen Köyü'nde halk İnanışları, büyüler, kargışlar, yakarışlar: Kavaközü derlemesi, Akademik Bakış Uluslararası Hakemli Sosyal Bilimler E-Dergisi, S. 10, 1-19.

Atnur, G. (2002). Başkurt ve Tatar efsaneleri üzerine karşılaştırmalı motif çalışması. (Yayınlanmamış Doktora Tezi), Atatürk Üniversitesi Sosyal Bilimler Enstitüsü, Erzurum.

Avcıoğlu, İ. (2017). Sebinkarahisar halk hekimliği uygulamaları. Ankara: Gece Kitaplığı.

Balcıoğlu, N. R. (1951). Ardahan havalisinde halk hekimliğinin kullandığı ilâçlar. Türk Folklor Araştırmaları, 2 (26), 414.

Bayar, M. (2014). Şebinkarahisar yöresinde ziyaret yerleri ile ilgili inanç ve uygulamalar. Karadeniz Araştırmaları, Sayı 41, 180-207.

Bayat, F. (2018). Türk mitolojik sistemi 2. İstanbul: Ötüken Yayınları.

Baysal, N. (2014). Geleneksel ve değiş̧im ekseninde Trabzon halk hekimliği üzerine bir araştırma. Ankara: Gece Kitaplı̆̆ı. 
doğrultuda Gümüşhane, Amasya, Tokat, Çorum gibi şehirlerde kuşburnu fabrikaları bulunmaktadır. Ayrıca kök boyacılıkta kırmızı rengi vermek için de kuşburnundan yararlanılır. (Akçiçek, 1997: 173)

Kültür Turizm Bakanlığı arşivine Gümüşhane adına tescil ettirilmiş bir de kuşburnu düdüğü bulunmaktadır. Mahmut Polat, kuşburnu ağacından bir tür nefesli çalgı aleti yaparak Gümüşhane Kelkit'te bir asır önce bilinen ve unutulmuş olan kuşburnu düdügünü 2010 yılında Türk kültürüne yeniden kazandırmıştır. Kuşburnu pek çok alanda sağladığı faydaları ile her geçen gün kıymetini artırmaktadır. Gümüşhane'de her yıl ağustos ayı içerisinde Kuşburnu-Pestil Kültür ve Turizm Festivali düzenlenmektedir. (KK.6)

\section{Sonuç}

Kuşburnu, Anadolu coğrafyası ve Türk dünyasında olumlu ve olumsuz yönleriyle karşımıza çıkan bir ağaç türüdür. Dîvânü Lugât'it Türk’te ağaçların kötüsü olarak nitelendirilmiştir. Dikenli bir ağaçtır ve Türk mitolojisinde dikenli ağaçlara yüklenen bir fonksiyon vardır. Altaylar'da ve Sibirya'da kötü ruhları korkutmada kuşburnu çalısı kullanılır.

Kuşburnu özellikle İç Anadolu ve Doğu Anadolu bölgesinde çok yetişen bir ağaç türüdür. Söz konusu bu bölgelerin iklim ve bitki örtüsü türü kuşburnu ağacının yetişmesine elverişlidir. Buna bağlı olarak bu bölgelerde halk arasındaki inanıșları ve ișlevleri de çok fazladır. Nazara ve kötü ruhların zararlarına karşı kuşburnu ağacı çevresinde ritüeller gelişirken bolluk ve bereketi artırmak, halk takvimini belirlemek, aydaş çocukları yürütmek için de kuşburnuna dair çeşitli uygulamalar gerçekleşmektedir. 0 aroması ve tadı ile bir taraftan Türk mutfağını süslerken diğer taraftan çayı, püresi, yağı ve sirkesi ile çeşitli hastalıklara şifa vererek alternatif tıpta yerini almıştır.

Kuşburnu sözlü halk edebiyatı ürünlerinde de karşımıza çıkmaktadır. Kuşburnu ağacı, meyvesi ve ürünleri hakkında âşıklar şiirler icra etmişlerdir. Bu konuda türküler söylemiş ve maniler düzülmüştür. Ayrıca kuşburnu üzerine tespit edebildiğimiz iki tane efsane bulunmaktadır.

Kuşburnunun çeşitli sektörlerde kullanımı her geçen gün artmaktadır. Kuşburnu genellikle kendi kendine yetişen, özel bir emek gerektirmeyen bir ağaç türü olduğu için kolaylıkla yetiştirilebilir. Günümüzde çok çeşitli sektörlerde kullanılan kuşburnunun ürün çeşitliliği artırılabilir. Bu sayede milli servete katkı sağlamanın yanı sıra açılacak fabrikalarda çok sayıda insan istihdam edilir.

\section{Kaynakça}

Acar, İ. H. (1976). Bilmece bildirmece, Sivas: Emek Matbaası.

Aça, M. (2008). Trabzon-Şalpazarı Çepnileri ile Çuvaş Türklerinin doğum sonrası etrafındaki inanış ve uygulamaları üzerine bir karşılaștırma denemesi. Karadeniz, Y: 1, S. 1, 21-34.

Akçiçek, E. (1997). Eren'ce halk bilim yazıları. İzmir: Güneşim Ofset.

Aker, A. U. (Tarihsiz). Hicranı anlayan şehir, Bayburt: Özer Ofset.

Arı, B. ve Top M. B. (2017). Hatay'da sağlık sorunlarını gidermek için başvurulan başlıca halk hekimliği uygulamaları. Karadeniz, S.33, 55-67.

Arslan, A. (2006). Ankara Türkmen Köyü'nde halk İnanışları, büyüler, kargışlar, yakarışlar: Kavaközü derlemesi, Akademik Bakış Uluslararası Hakemli Sosyal Bilimler E-Dergisi, S. 10, 1-19.

Atnur, G. (2002). Başkurt ve Tatar efsaneleri üzerine karşılaştırmalı motif çalış̧ması. (Yayınlanmamış Doktora Tezi), Atatürk Üniversitesi Sosyal Bilimler Enstitüsü, Erzurum.

Avcıŏglu, İ. (2017). Şebinkarahisar halk hekimliği uygulamaları. Ankara: Gece Kitaplığı.

Balcıoğlu, N. R. (1951). Ardahan havalisinde halk hekimliğinin kullandığı ilâçlar. Türk Folklor Araştırmaları, 2 (26), 414.

Bayar, M. (2014). Şebinkarahisar yöresinde ziyaret yerleri ile ilgili inanç ve uygulamalar. Karadeniz Araștırmaları, Sayı 41, 180-207.

Bayat, F. (2018). Türk mitolojik sistemi 2. İstanbul: Ötüken Yayınları.

Baysal, N. (2014). Geleneksel ve değiş̧im ekseninde Trabzon halk hekimliği üzerine bir araştırma. Ankara: Gece Kitaplı̆̆ı. 
Begiç, H. N. (2013). Ankara Kazan ve çevresinde halk hekimliği. 2. Uluslararası Ankara-Kazan ve Çevresi Halk Kültürü Sempozyumu ve Uluslararası Sanat Çalıştayı, 288-293.

Berger, H. (2000). Çingene mitolojisi. (Çev. M. Yaşar Sağlam), Ankara: Ayraç Yayınları.

Boratav, P. N. (1984). 100 soruda Türk folkloru (İnanışlar, Töre ve Törenler, Oyunlar). İstanbul: Gerçek Yayınevi.

Bulut, İ. (2011). Anadolu'da inanışların ve geleneklerin doğa korunması açısından önemi üzerine örnekler. Atatürk Üniversitesi Edebiyat Fakültesi Dergisi, C.11, S.46, 119-134.

Çelik, A. Kuruca, N. (2000). Şebinkarahisar'da halk inanmaları. Şebinkarahisar I. Tarih ve Kültür Sempozyumu 30 Haziran-1 Temmuz 2000. İstanbul: Şebinkarahisar Belediyesi Yayınları, 333354.

Çolak, F.(2015). Yazılı ve sözlü belgeler ışığında Niğde halk hekimliği. Konya: Kömen Yayınları.

Demiray, M. G. (1976). Zile'den maniler ve Gemerek'ten birkaç deyim ve kelime. Sivas Folkloru, Y. 4, S.46, 16.

Dikme, N. (2018). Pülümür ve çevresindeki halk inanışları. (Yayınlanmamış Yüksek Lisans Tezi). Ankara Üniversitesi Sosyal Bilimler Enstitüsü, Ankara.

Doğan, Ș. (2013). Elazı̆̆ İli Keban İlçesi halk inanışları. (Yayınlanmamış Yüksek Lisans Tezi). Fırat Üniversitesi Sosyal Bilimler Enstitüsü, Elazığ.

Duman, T. (2014). Kuşburnu (Rosa Canina) nektarında toplam fenolik madde ve suda çözülen vitaminlerin ısıl parçalanma kinetiği. (Yayınlanmamıș Yüksek Lisans Tezi). Pamukkale Üniversitesi Fen Bilimleri Enstitüsü, Denizli.

Dursun, S. (2008). Kuzeydoğu'da mizah ve duygu esintileri. Ankara: İsmat Yayınları.

Eliade, M. (1999). Şamanizm. (Çev.: İsmet Birkan), Ankara: İmge Kitapevi.

Emir, D. A. (1987). Bayburt manileri- bilmeceleri, İstanbul: Eğitim Yayınları.

Emir, D. A. (2009). Bayburt efsaneleri. İstanbul: Nef Yayıncılık.

Ergun, P. (2012). Türk Kültüründe ağaç kültü, Ankara: Atatürk Kültür Merkezi Başkanlığı Yayınları.

Gökbel, A. (2002). Şarkışla yöresinde ziyaret yerleri ile ilgili inanç ve uygulamalar. Cumhuriyet Üniversitesi İlahiyat Fakültesi Dergisi, VI/1, Sivas, 1-16.

Gökyay, O. Ş. (2006). Dede Korkut hikâyeleri. İstanbul: Kabalcı Yayınevi.

Gökçimen, A. (2005). Artvin İlinin Sanbudak Köyünde nazarla ilgili inanışlar. A.Ü. Türkiyat Araştırmaları Enstitüsü Dergisi, S.27, Erzurum, 197-201.

Irmak, Y. (2018). Bingöl halk hekimliği. Bingöl Üniversitesi Bingöl Araştırmaları Dergisi, C.5, S.1, 4975.

İnan, A. (1986). Tarihte ve bugün Şamanizm. Ankara: Türk Tarih Kurumu Basımevi.

Kalafat, Y. (2017). Karir Zaza-Türk halk inançları, İstanbul Hukuk Mecmuası, C.75, 407-426.

Karabüber, T. (2017). Tosya halk inanışları. (Yayınlanmamış Yüksek Lisans Tezi). Çankırı Karatekin Üniversitesi Sosyal Bilimler Enstitüsü, Çankırı.

Karakaş, A. (2015). Osmaniye ve çevresi halk hekimliğinde dinsel-büyüsel uygulamalar. Sosyal Bilimler Dergisi, Y: 2, S:5, 156-166

Karakuș, İ. (2006). Keskin manileri. Ankara: Yüce Erek Yayınevi.

Kâşgarlı Mahmut. (2006). Dîvânü Lügat'it-Türk I. (Çev. B. Atalay), Ankara: TDK Yayınları.

Kaya, D. (2002). Sivas'ta yatmakta olan Horasan merkezli Anadolu erenleri. Halkbilim Araştırmaları. Kitabevi Yayınları: İstanbul, 261-285. 
Kesgin, T, M. Özcebe H. (2004). Türkiye'de çocuk bakımındaki geleneksel inanç ve uygulamalar. Türkiyat Araştırmaları, S.1.43-56.

Kılıç, S. (2012). Sivas İli Ulaş İlçesi halk inanışları. (Yayınlanmamış Yüksek Lisans Tezi). Fırat Üniversitesi Sosyal Bilimler Enstitüsü, Elazığ.

Kırtan, M. (1991). Bayburtluca. Gazi Bayburt Aylık Yerel Dergi, S. 5, Bayburt, 14.

Kurtuluş, İ. (2010). Güney Azerbaycan ve Kıbrıs bilmecelerinin karşılaştırılması. (Yayınlanmamış Yüksek Lisans Tezi). Yakın Doğu Üniversitesi Atatürk Eğitim Fakültesi, , Lefkoşa.

Kuzucular, E. (1978). Şarkışla'da yabani bitkilerden yapılan yiyecekler. Sivas Folkloru, Yıl 6, S.66, 24.

Lvova, E. L. , Oktyabrskaya İ. V. , vd. (2013). Güney Sibirya Türklerinin geleneksel dünya görüşleri (kâinat ve zaman. nesneler dünyası). (Çev. Metin Ergun). Konya: Kömen Yayınları.

Potapov L.P. (2012). Altay Şamanizmi. Konya: Kömen Yayınları.

Roux, J.P. (1994). Türklerin ve Moğolların eski dini. (Çev: Aykut Kazancıgil). İstanbul: İşaret Yayınları.

Okutan, H. T. (1949). SSebinkarahisar ve civarı. Giresun: Yeşil Giresun Matbaası.

Ocak, A. Y. (1983). Bektaşî menakıblarında İslâm öncesi inanç motifleri, İstanbul: Enderun Kitabevi.

Ögel, B. (2010). Türk mitolojisi I. Ankara: Türk Tarih Kurumu Yayınları.

Ögel, B. (2014). Türk mitolojisi II. Ankara: Türk Tarih Kurumu Yayınları.

Öncül, K. (2011). Kuzey Doğu Anadolu bölgesi halk hekimliği (Kars-Iğdır). Kafkas Üniversitesi Türk Halkbilimi Uygulama ve Araştırma Merkezi Yayınları: 2, E-Kitap https://docplayer.biz.tr/976845-Kuzeydogu-anadolu-bolgesi-halk-hekimligi-kars igdir.html.

Öz M., Baltacı C., Deniz İ. (2018). Gümüşhane yöresi kuşburnu (Rosa canina L.) ve siyah kuşburnu (Rosa pimpinellifolio L. ) meyvelerinin C vitamini ve şeker analizleri, GÜFBED/GUSTIJ, 8 (2), 284-292.

Özdemir, C. (2009). Havza İlçesinin genel folklorik yapısı. Uluslararası Sosyal Araștırmalar Dergisi, Volume 2/7, Spring, 185-206.

Özkan, T. (2012). Geleneksel tıptan modern Tıbba Ocaklık Kurumu: Ankara İli Çubuk İlçesi Örneği. (Yayınlanmamış Doktora Tezi). Ankara Üniversitesi Sosyal Bilimler Enstitüsü, Ankara.

Sever, M. (2004). Türk halk inançlarında ve halk hekimliği uygulamalarında meyve. TÜBAR-XVI, 95109.

Sever, M. (2016). Mersin ve yakın çevresinde halk inançları ve halk hekimliği. Ankara: Barış Kitap.

Sevindirici R. ve Sevindirici İ. (1986). Halk bilmeceleri. Ankara: Evrensel İletişim Yayınları.

Sezmiş, M.E. (2018). Kültürel değişim bağlamında Zile İlçesinde Türk halk inanışları. (Yayınlanmamış Yüksek Lisans Tezi) Ondokuz Mayıs Üniversitesi Sosyal Bilimler Enstitüsü, Samsun.

Şar, S. (2011). Bazı üzümsü meyvelerin kullanımlarının eczacılık ve tıp tarihi açısından incelenmesi. Lokman Hekim Journal, 1 (2), 1-6.

Tanyu, H. (1973). Dinler tarihi araştırmaları. Ankara: Ankara Üniversitesi İlahiyat Fakültesi Yayınları.

Tanyu, H. (1975). Türklerde ağaçla ilgili inançlar. Folklor Araştırmaları Yıllığı. Ankara: Ankara Üniversitesi Basımevi.

TRT. (2006). Türk halk müziği sözlü eserler antolojisi 1-2. (2.Baskı), Ankara: Türkiye Radyo Televizyon Kurumu Müzik Dairesi Başkanlı̆̆ı, TRT Müzik Dairesi Yayınları, No:98.

Yağmur, M. A. (1996). Kayseri İli halk hekimliği. Türk Halk Kültürü Araştırmaları, HAGEM: 236, Ankara: Kültür Bakanlığı Yayınları, 111-115.

Yardımcı, M. (1999). Türk halk bilimi ve edebiyat araștırmaları. Ürün Yayınları: Ankara. 
URL-1: http://www.turkuler.com/sozler/turku_kusburnu_derde_derman.html. (28.04.2017)

*Bu derlemeler 2017 yılında yapılmıştır.

Kaynak Kişi 1: Mustafa Kayalı, 1967 doğumlu, hizmetli, lise mezunu, Bayburt/ Merkez

Kaynak Kişi 2: Gülten Galacoş: 1972 doğumlu, ev hanımı, ilkokul mezunu, Bayburt Çiğdemtepe Köyü.

Kaynak Kişi 3: Emine Gürer: 1968 doğumlu, ev hanımı, ilkokul mezunu, Gümüşhane/ Merkez.

Kaynak Kişi 4: Gül Kaymak, 1983 doğumlu, ev hanımı, ortaokul mezunu, Bayburt/ Merkez.

Kaynak Kişi 5: Esra Özbey, 1982 doğumlu, ev hanımı, üniversite mezunu, Erzurum/ Merkez.

Kaynak Kişi 6: Turan Gürer: 1966 doğumlu, imam, üniversite mezunu, Gümüşhane/Merkez.

Kaynak Kişi 7: Dilek Sağlam: 1979 doğumlu, ev hanımı, ortaokul mezunu, Bayburt/Merkez.

\section{Extended Abstract}

There are various beliefs and practices regarding trees and tree species in the Turkish world. These beliefs, which still live vividly today, are based on the pre-Islamic period. The pre-Islamic belief system and the cult of trees have blessed some trees in Turkish culture. Juniper, beech, sycamore and birch tree are mythological trees considered sacred according to ancient Turkish beliefs. Likewise, the rosehip tree is a type of tree on which various legends are told in mythological narratives.

The rosehip tree, known by different names in various parts of Anatolia, also has an important place in Turkish beliefs and practices. It also shows the peculiarity of a mythological plant. It has been described as the worst of the trees in Divan-I Lugât'it Türk. This function, which is attributed to the rosehip tree, continues to exist in some cities today. Rosehip tree is considered the habitat of evil beings such as gin, etc. In Şebinkarahisar, rosehip is described as a haunt of uncanny beings. Rosehip appears with various functions in rituals of transition from birth to death. Rosehip branch is used in applications the made for "aydas (sick, weak) children". People who have no children or die their children hang a rosehip branches in front of their homes. There are sacred tombs where various rituals are practiced around some rosehip trees. In this context, cloth, ribbons or laundry are attached to the rosehip trees around the tomb. At the same time, the rosehip tree is thought to bring abundance and fertility. For this purpose, rosehip is buried on the threshold of the house in some cities in the Central Anatolia region. It is believed that when rosehip is very much in the folk calendar, the winter will last long. Rosehip branch and thorn are also used to protect against the evil eye. While the branch, tree and thorn of rosehip appear in various ways in public beliefs, especially the fruit of rosehip has been one of the healing methods in folk medicine. Rosehip fruit, which contains very useful vitamins, especially vitamin $C$, is used in the treatment of various diseases. Tea made from rosehip fruit is consumed in cases of flu, colds, chills and coughs. In disorders such as hemorrhoids, diarrhea, yeast; rosehip tea as well as rosehip paste or puree are consumed. While the oil obtained from rosehip tree is good for rheumatism, in Sivas this rosehip and hazelnut oil is mixed and used to treat infertility.

Rosehip has also been the subject of folk literature products such as folk songs, manis, riddles and legends. In many parts of Anatolia, folk songs were sung and manis were told on rosehip. In this study, two legends about rosehip are included. In one of these legends, rosehip is called a wild rose.

Besides all these functions, rosehip has also been food in a culinary culture where different flavors are made. Marmalade and jam are made from the extract obtained by boiling rosehip fruit. Rosehip soup is also made in Bayburt, Gümüşhane and Erzurum regions. This soup, which is called Kokoc or Sweet soup in Bayburt and contains wheat, grapes and plums, resembles a kind of ashura. Rosehip soup, which also has an important place in the cultural sense, is served as a treat especially during the holidays and is distributed as ashura in Muharrem.

Rosehip is known as an important tree and fruit in Turkish mythology, Turkish folk beliefs, folk medicine, culinary culture. Rosehip's tree, branch, fruit are used for many purposes and today, rosehip is used in different fields. Products containing rosehip are increasing day by day. In addition to being used in the pharmaceutical industry, rosehip is used in baby foods, pastry sauces and jellies. Rosehip, which is processed in factories for various purposes, thus contributes to the country's economy. Rosehip is extremely important especially in the cities of Gümüşhane and Bayburt. With rosehip collected in autumn, a wheel-shaped dried fruit roll-up called kokoc is made. In 2010, the forgotten rosehip whistle was reintroduced to the Gumuşhane culture by a citizen of Gümüşhane with a wind instrument made from a rosehip branch. 